REPOSITOR, Vol. 2, No. 7, Juli 2020, Pp. 905-914

ISSN : 2714-7975

E-ISSN :2716-1382

\title{
Analisis Sentimen Konten Radikal dalam Kontestasi Politik 2019 di Media Twitter Menggunakan Interjection dan Punctuation
}

\author{
Taufik Nurahman ${ }^{\star 1}$, Yufis Azhar ${ }^{2}$, Nur Hayatin ${ }^{3}$ \\ 1,2,3Teknik Informatika/Universitas Muhammadiyah Malang \\ tnurahman@gmail.com¹, yufis.az@gmail.com² ,noorhayatin@gmail.com³
}

\begin{abstract}
Abstrak
Analisis sentiment saat ini menjadi tren untuk mengidentifikasi opini serta emosi seseorang dalam menanggapi sebuah situasi. Di tahun politik, sangat banyak opini bertebaran baik yang dituliskan di media cetak maupun media sosial. Para pelaku politik memiliki pandangan yang berbeda-beda, sehingga memunculkan banyak opini yang berujung pada tindakan radikal seperti perlakuan SARA kepada orang yang berbeda pandangan. Penelitian terkait dengan analisis sentimen radikal melalui media twitter sudah dilakukan oleh beberapa peneliti sebelumnya, namun belum ada penelitian analisis sentimen radikal yang menggunakan fitur ekstraksi. Penelitian ini mengusulkan untuk melakukan analisis sentimen konten radikal pada tweet tekstual berbahasa Indonesia terkait dengan kontestasi politik di Indonesia yang lalu menggunakan dua fitur yakni punctuation dan interjection, serta diklasifikasikan menggunakan algoritma support vector machine. Dari hasil klasifikasi yang telah dilakukan, didapatkan nilai akurasi dari analisis sentimen sebesar $80 \%$ dan dilakukan analisis sentiment radikal beberapa kali dengan jumlah interjection yang berbeda, didapatkan hasil akurasi sebesar 94\% dengan menggunakan 200 kata interjection.
\end{abstract}

Kata Kunci: Interjection, Punctuation, Support Vector Machine, Analisis Sentimen, Radikal

Sentiment analysis is now a trend to identify people's opinions and emotions in responding to a situation. In the political year, many opinions were scattered both written in print and social media. Political actors have different views, so that raises a lot of opinions that lead to radical actions such as SARA to people with different opinions. Research related to the analysis of radical sentiments via Twitter has been done by several researchers before, but there have been no studies of radical sentiment analysis using extraction features. This study proposes to conduct a radical content sentiment analysis on Indonesian textual tweets related to political contestation in Indonesia which then uses two features namely punctuation and interjection, and is classified using the support vector machine algorithm. From the results of the classification that has been done, obtained an accuracy value of $80 \%$ sentiment analysis and radical sentiment analysis conducted several times with a number of different interjection, obtained an accuracy of $94 \%$ using 200 interjection words.

Keywords: Interjection, Punctuation, Support Vector Machine, Sentiment Analysis, Radical

\section{Pendahuluan}

Twitter merupakan salah satu media sosial yang memiliki jumlah basis pengguna yang sangat besar. Pertumbuhan pengguna Twitter sangatlah pesat hingga bulan Januari 2013 diketahui jumlah pengguna terdaftar mencapai 500 juta akun di seluruh dunia [1]. Bahkan, dalam penelitian yang dilakukan oleh Ghulam Asrofi Buntoro pada tahun 2016 dan diketahui jumlah pengguna yang terdaftar sebanyak 106 juta akun di Indonesia dan terus bertambah sebanyak 300.000 setiap harinya [2]. Salah satu negara yang memiliki basis pengguna terbesar Twitter adalah Indonesia, dimana penggunanya cenderung hyper aktif dalam platform tersebut.

Penggunaan platform media social Twitter yang cenderung mudah dipakai oleh berbagai kalangan usia menjadikan Twitter sebagai salah satu platform utama dalam bertukar pendapat, menceritakan keseharian, sampai pada mengemukakan pendapat atau opini atas suatu isu. Kecenderungan pemakaian Twitter meningkat dalam segi kuantitas tweet (postingan di dalam twitter) terutama pada masa tahuntahun politik di Indonesia, dimana opini publik oleh berbagai kalangan masyarakat meramaikan platform tersebut. Aktivitas melakukan posting berbagai tweet 
dalam isu-isu politik menjadi hal yang bersifat adiktif. Hal tersebut dalam beberapa kurun waktu terrakhir, menjadi penyebab terciptanya hashtags ikonik dari beberapa golongan masyarakat yang hingga saat ini digunakan sebagai simbol atau representasi dari suatu ide oleh kelompok tertentu di dalam Twitter.

Hashtag ikonik dalam platform Twitter menjadi perwakilan atas sebuah ide yang dicanangkan terhadap isu tertentu. Beberapa hashtag popular dan yang paling menonjol beberapa waktu belakangan ini seperti \#2019GantiPresiden dan \#2019TetapJokowi dengan bebagai macam isi tweet di dalamnya. Hashtags tersebut tentunya berpengaruh terhadap arah berpendapat dari para pengguna twitter di Indonesia saat ini.

Pengaruh di dalam hashtags yang bermuatan politik memiliki efek terhadap penggiringan opini publik dimana terdapat dua jenis yakni menggiring kepada arah positif dan juga ke arah negative seperti munculnya Hatespeech serta tweet yang mengandung opini radikalisme dari sebuah kelompok untuk mempengaruhi persepsi pengguna lain yang sebenarnya tidak terlibat di dalamnya. Kemunculan beberapa hashtags ikonik bermuatan politik juga diprakarsai oleh beberapa tweet yang juga di akomodir serta di follow up oleh tokoh-tokoh utama dari pelaku politik di Indonesia. Kuantitas tweet yang berkaitan dengan hashtag ikonik bermuatan politik, didukung dengan adanya trend yang memunculkan tweet-tweet tersebut sebagai wajah dari Twitter pada kurun waktu tertentu menjadikan semakin banyak orang untuk bergabung dan saling lempar opini atas nama hashtag tersebut. Kondisi ini berujung pada munculnya sifat sentimental dari beberapa orang yang bersifat ekstrem atau militan terhadap pihak yang mewakili nilai-nilai yang berlawanan dengan ide yang direpresentasikan dalam hashtag ikonik, misalnya calon presiden dan wakil presiden yang berlawanan dari penggagas hashtag. Situasi ini berujung pada terciptanya suasana yang tidak kondusif sehingga lagilagi berujung pada terciptanya kata umpatan untuk suatu kelompok seperti 'Cebong' dan 'Kampret'.

Pasca digunakannya kedua istilah umpatan itu dalam setiap opini yang di publikasikan melalui media twitter secara masif, kemudian terjadilah penggiringan opini yang berakibat pada opini berpolitik yang dimbumbui dengan aroma radikalisme dan ekstrimisme atas dasar sentimental satu sama lain yang mulai terjadi akhir-akhir ini. Isu-isu Suku, Agama, Ras, dan Antargolongan (selanjtnya disebut SARA) mulai dimunculkan lagi dan yang paling menonjol ialah politisasi agama yang didalamnya terdapat penggiringan pengkafiran terhadap sesama muslim (selanjutnya disebut takfiri) serta penggiringan opini kepada tindak anarkis. Hal tersebut tentu ditakutkan mengurangi esensi publik terhadap pesta demokrasi itu sendiri dan akan berakibat fatal dengan kurangnya kepercayaan masyarakat pada proses pemilihan umum (selanjutnya disebut pemilu) yang akan berlangsung.

Beberapa penelitian mengenai analisis sentiment telah menunjukan hasil yang berbeda seperti pada penelitian ini [3] menganalisa sentiment konten radikal terorisme dari media twitter dengan menggunakan tweet berbahasa Indonesia. Tweet radikal tersebut diklasifikasikan menjadi 2 yakni radikal negative dan radikal positif namun tingkat akurasi yang didapatkan masih sebesar $70 \%$. Namun pada penelitian [4] membahas tentang deteksi sarkas pada tweet berbahasa Indonesia menggunakan dua buah feature extraction yakni punctuation dan interjection lalu mengklasifikasikannya menggunakan naïve bayes classifier dan k-Nearest Neighbor. Hasil akhir yang didapatkan mesin hanya mampu mengklasifikasikan sedikit tweet positif sarkasme dari dua kelas yang diberikan menggunakan naïve bayes. Dibuktikan dengan nilai Akurasi sebesar $70 \%$. Namun, menggunakan kNearest Neighbor akurasi yang didapatkan sudah cukup baik yakni sebesar $82 \%$.

Peneliti kemudian tertarik untuk melakukan penelitian atas isu penggunaan platform Twitter yang memuat konten radikal dalam kontestasi politik 2019 dengan menganalisis sentiment yang termuat di dalamnya. Penelitian Peneliti didasarkan pada beberapa penelitian terdahulu di atas, namun dalam penelitian ini diusulkan sentiment analisis terhadap konten radikal pada tweet berbahasa Indonesia terkait dengan kontestasi politik di Indonesia dengan menggunakan metode Support Vector Machine yang ditambahkan Fitur Ekstraksi Interjection dan Punctuation sebagai fitur untuk mendeteksi tweet dengan maksud radikal. Titik perbedaan penelitian ini dengan sebelumnya ialah penggunaan metode Support Vector Machine di tambahkan dengan fitur ekstraksi Interjection dan Punctuation yang diharapkan dapat meningkatkan akurasi.

REPOSITOR, Vol. 2, No. 7, Juli 2020: 905-914 


\section{Metode Penelitian}

\subsection{Analisa Dataset}

Data yang akan digunakan pada penelitian ini merupakan tweet berbahasa Indonesia yang terkait dengan kontestasi politik Indonesia pada tahun 2019. Data yang digunakan sebanyak dua ribu tweet. Yang mana tweet tersebut mengandung keywords: \#2019GantiPresiden, \#Jokowi2Periode, Prabowo, Jokowi, Antek Aseng, dan Politisasi Agama. Tweet yang dimaksud memiliki hubungan dengan makna dari radikal [5]. Data tweet yang berjumlah dua ribu tersebut akan di pecah kedalam bentuk data latih dan data uji, dengan rasio $80 \%$ data latih dan $20 \%$ data uji, serta rasio pembagian antara data negatif dan positif masing-masing $50 \%$ dari total data.

\subsection{Lingkungan Kerja}

Penelitian ini tentunya membutuhkan Software dan Hardware guna menunjang proses analisis sentimen. Hal ini diperlukan untuk menentukan pendapat dan subjektivitas dalam sebuah teks sebagai bagian dari analisis sentiment [6]. Pada penelitian ini menggunakan software yang ditunjukkan pada Tabel 1 berikut.

\begin{tabular}{cc} 
& Tabel 1. Perangkat Lunak \\
\hline No & Spesifikasi \\
\hline 1 & Python versi 3.7 \\
2 & Jupyter Notebook \\
3 & Library NLTK versi 3.4 \\
4 & Library Scikit_learn versi 0.21 .3 \\
5 & Library Sastrawi versi 1.2.0 \\
\hline
\end{tabular}

Hardware yang digunakan pada penelitian ini, ialah menggunakan sebuah laptop merk ASUS ROG tipe G550JX dengan spesifikasi perangkat keras yang ditunjukkan pada Tabel 2 berikut.

Tabel 2. Perangkat Keras

\begin{tabular}{lc}
\hline No & Spesifikasi \\
\hline 1 & Processor Intel Core i7-4720HQ CPU @ 2.60Ghz \\
2 & RAM 8 GB DDR3 \\
3 & Harddisk 1 TB \\
\hline
\end{tabular}

\subsection{Pengumpulan Data atau Crawling}

Data yang akan digunakan akan dapatkan melalui media sosial Twitter berdasarkan kriteria yang telah di jelaskan pada bagian Analisa Dataset. Seperti pada Tabel 3, crawling dilakukan dengan menggunakan tool TwitterScraper. Untuk menggunakan tool TwitterScraper ini sangat mudah. Namun, diperlukan instalasi library TwitterScraper terlebih dahulu. Jika telah dilakukan instalasi, proses Crawling dapat dilakukan dalam Command Prompt dengan mengetikkan syntax dari tool TwitterScraper:

Tabel 3. Contoh Data yang telah di Crawling

\begin{tabular}{|c|c|}
\hline No & Tweet \\
\hline 1. & $\begin{array}{l}\text { Emang loe kira Prabowo Pribumi? Kagak liat kakaknya Cina juga? Bapak } \\
\text { nya Cina ibunya cina? Terus Prabowo } \\
\text { Pribumi sendiri? Brojol dari mana? } \\
\text { (a) }(2) \text { (2) }\end{array}$ \\
\hline 2. & $\begin{array}{l}\text { Rakyat sudah tahu jok, } \\
\text { Jokowi (01) didukung kelompok politisi preman, Syiah, liberal, munafikun } \\
\text { dan pemuja PKI. } \\
\text { Pak Prabowo }(02) \text { didukung kelompok religius lurus dan politisi santun } \\
\text { serta rakyat cerdas yang waras. } \\
\text { Faham antum??? } \\
\text { \#01vsrakyatreligiuslurus } \\
\text { \#02vsPKI }\end{array}$ \\
\hline
\end{tabular}




\subsection{Analisa dan Perancangan}

Tahapan yang akan dilakukan untuk melakukan analisis sentiment dilanjutkan dengan deteksi sarkasme pada penelitian ini dapat dilihat pada Gambar 1.

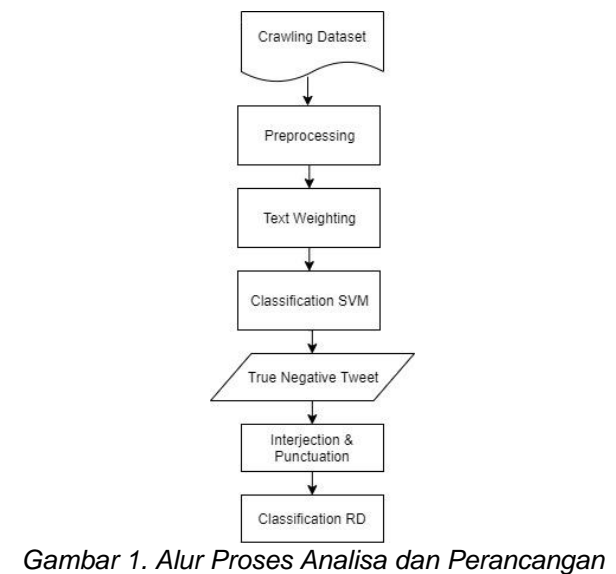

Pada Gambar 1 di atas merupakan alur proses Analisa dan perancangan yang mana bagian-bagian dari alur tersebut akan di jelaskan pada sub bab di bawah ini.

\subsubsection{Preprocessing}

Untuk melakukan preprocessing tahapan yang dilakukan adalah case folding, filtering, dan stemming [7].

Terdapat 4 proses dalam melakukan preprocessing yaitu :

a. Labelling

Pada tahap ini, data yang telah di crawling akan di beri label terlebih dahulu. Data akan di labeli sebagai tweet yang positif atau tweet yang negatif secara manual.

\section{b. Case Folding}

Pada tahap Case Folding, huruf kapital dan non kapital pada semua tweet yang telah di crawling akan di setarakan. Contoh hasilnya dapat dilihat pada Tabel 4 di bawah.

\begin{tabular}{cl} 
& Tabel 4. Case Folding pada Dataset \\
\hline Tahap & \multicolumn{1}{c}{ Tweet } \\
\hline Awal & $\begin{array}{l}\text { Emang loe kira Prabowo Pribumi? Kagak liat kakaknya } \\
\text { Cina juga? Bapak nya Cina ibunya cina? Terus } \\
\text { Prabowo } \\
\text { Pribumi sendiri? Brojol dari mana? }\end{array}$ \\
\hline Hasil case & $\begin{array}{l}\text { emang loe kira prabowo pribumi? kagak liat kakaknya } \\
\text { cina juga? bapak nya cina ibunya cina? terus prabowo } \\
\text { pribumi sendiri? brojol dari mana? }\end{array}$ \\
\hline
\end{tabular}

Pada Tabel 4 di atas, perbedaan dari hasil case folding dengan data awal telah terlihat dengan kata "Emang" yang memiliki huruf kapital, menjadi "emang" yang mana huruf kapital tadi telah di ubah ke bentuk huruf kecil.

\section{c. Filtering}

Data yang telah melewati case folding tentunya masih menyisakan hal seperti Username, URL, Hashtag, tanda baca, ataupun Retweet. Pada tahap ini akan dilakukan penghapusan pada bagian-bagian tersebut seperti yang di tampilkan pada Tabel 5 di bawah ini.

REPOSITOR, Vol. 2, No. 7, Juli 2020: 905-914 


\begin{tabular}{cl} 
& Tabel 5. Filtering pada Dataset \\
\hline Tahap & \multicolumn{1}{c}{ Tweet } \\
\hline \multirow{2}{*}{ Awal } & \begin{tabular}{l}
\multicolumn{1}{c}{ emang loe kira prabowo pribumi? kagak liat } \\
kakaknya cina juga? bapak nya cina ibunya cina? \\
terus prabowo \\
pribumi sendiri? brojol dari mana?
\end{tabular} \\
\hline \multirow{3}{*}{ Hasil filtering } & $\begin{array}{l}\text { emang loe kira prabowo pribumi kagak liat kakaknya } \\
\text { cina juga bapak nya cina ibunya cina terus prabowo } \\
\text { pribumi sendiri brojol dari mana }\end{array}$ \\
\hline
\end{tabular}

Pada tabel di atas, dapat dilihat bahwa tanda tanya (?) yang ada pada data awal di hapus, sehingga tidak terdapat lagi pada data pasca melewati tahap filtering.

\section{d. Tokenizing}

Tahap ini mengubah data yang sebelumnya berbentuk kalimat menjadi potonganpotongan per-kata seperti contoh pada Tabel 6

\begin{tabular}{cl} 
Tabel 3.4 Stemming pada data setTabel 6. Tokenizing pada Dataset \\
\hline Tahap
\end{tabular}

Pada tabel diatas, terlihat perbedaan data awal dengan data yang telah melewati fase tokenizing. Data yang sebelumnya berbentuk kalimat, berubah menjadi potongan per-kata.

\section{e. Stopword Removal}

Tahap ini merupakan tahap penghapusan pada kata-kata yang tidak di butuhkan. Contoh hasilnya dapat dilihat pada Tabel 7.

\begin{tabular}{cl} 
Tabel 3. 4 Stemming pada data setTabel 7. Stopword Removal pada Dataset \\
\hline Tahap & \multicolumn{1}{c}{ Tweet } \\
Awal & $\begin{array}{l}\text { emang loe kira prabowo pribumi kagak liat kakaknya } \\
\text { cina juga bapak nya cina ibunya cina terus prabowo } \\
\text { pribumi sendiri brojol dari mana }\end{array}$ \\
\hline $\begin{array}{c}\text { Hasil Stopword } \\
\text { Removal }\end{array}$ & $\begin{array}{l}\text { Emang loe prabowo pribumi kagak liat kakak cina } \\
\text { nya cina cina prabowo pribumi brojol }\end{array}$ \\
\hline
\end{tabular}

Pada tabel diatas, terlihat perbedaan data awal dengan data yang telah di Stopword Removal. Terutama pada kata-kata yang tidak dibutuhkan, seperti "nya", "dari", dan sebagainya.

\section{f. Stemming}

Tahap ini merupakan tahap pencarian kata dasar pada kata yang berimbuhan. Contoh hasilnya dapat dilihat pada Tabel 8 berikut ini.

\begin{tabular}{cl} 
Tabel 3. 4 Stemming pada data setTabel 8. Stemming pada Dataset \\
\hline Tahap & \multicolumn{1}{c}{ Tweet } \\
\hline & Memang ada carut marut dlm segala pengelolaan di \\
& negara ini termasuk masalah kesehatan dan BPJS. \\
& Jika tidak mampu...serahkan pd yg mampu. \\
& InsyaAllah: \\
& \#2019GantiPresiden \\
& \#IndonesiaMenang \\
& \#2019PrabowoPresidenRI
\end{tabular}

$1+$

Formatted: Font: (Default) Arial, $10 \mathrm{pt}$, Indonesian

Formatted: Font: (Default) Arial, $10 \mathrm{pt}$, Indonesian

Formatted: Indent: Left: $0 \mathrm{~cm}$, Space Before: $0 \mathrm{pt}$, Line spacing: single, Don't keep with next

Formatted: Font: (Default) Arial, $10 \mathrm{pt}$, Indonesian Formatted: Indent: Left: $0 \mathrm{~cm}$, Space Before: $0 \mathrm{pt}$, Line spacing: single, Don't keep with next

Formatted: Font: (Default) Arial, 10 pt, Indonesian

Formatted: Font: (Default) Arial, $10 \mathrm{pt}$, Indonesian

Formatted: Indent: Left: $0 \mathrm{~cm}$, Space Before: $0 \mathrm{pt}$, Line spacing: single, Don't keep with next

Formatted: Font: (Default) Arial, 10 pt, Indonesian 
Hasil stemming negara ini masuk masalah sehat dan bpjs jika tidak mampu serah pd yg mampu insyaallah

gantipresiden indonesiamenang prabowopresidenri

Pada tabel diatas, kata berimbuhan akan di ubah menjadi bentuk dasarnya. Terdapat beberapa perbedaan dari data awal dengan data yang telah di Stemming. Contohnya seperti kata "pengelolaan" yang berubah menjadi "kelola" setelah di Stemming.

\subsubsection{Text Weighting}

Pada penelitian ini, data yang telah terstruktur pasca melewati fase preprocessing akan di beri perhitungan bobot dari masing-masing term menggunakan metode Bag of Words dari library ScikitLearn. Namun, langkah pertama sebelum di lakukannya penghitungan term, ialah melakukan pembagian antara data train dan data test. Data yang dibubuhi fitur ini akan diubah menjadi list string, dengan prinsip bag of words menghindari pengulangan kata. Yang mana nantinya akan membentuk feature vector yang disebut sebagai dimensi.

\subsubsection{Classification SVM}

Setelah melewati fase Preprocessing dan text weighting atau pembobotan kata. Data akan siap untuk di klasifikasikan, guna mendapatkan nilai true negative. Data akan di klasifikasikan menggunakan metode Support Vector Machine. Metode ini akan mencari sebuah hyperplane atau pembatas pada tiap-tiap antar kelas data yang memiliki margin atau jarak hyperplane pada data paling dekat dalam setiap kelasnya [8]. Algoritma dari metode Support Vector Machine yang akan digunakan adalah sekuensial dengan alur flowchart seperti Gambar 2 berikut [9]

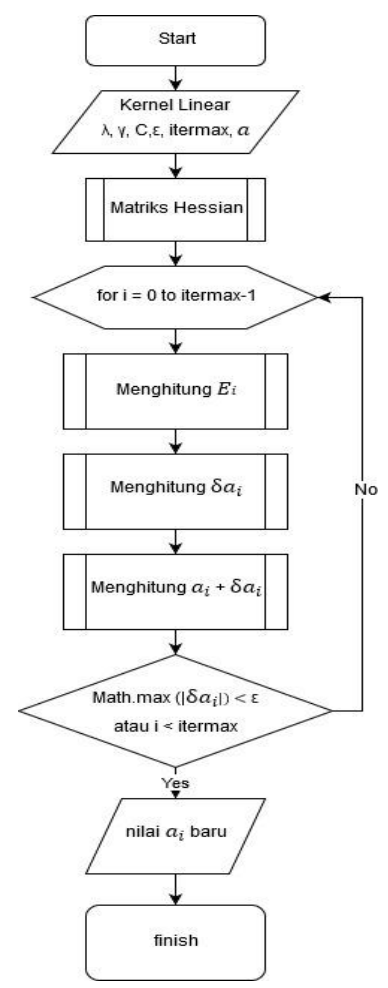

Gambar 2. Algoritma Sekuensial Support Vecttor Machine

REPOSITOR, Vol. 2, No. 7, Juli 2020: 905-914 
Penjelasan langkah-langkah Sekuensial dari Gambar 2 sebagai berikut[10] :

1. Menginisialiasi parameter $\lambda$ (variable scalar), Y (Learning Rate), C (variable Slack), $\varepsilon$ (eplison) dan iteraksi maksimum

2. Menginisialisasi $a i=0$. kemudian menghitung Matrik Hessian berikut $D_{i j}=y_{i} y_{j}\left(K\left(x_{i}, x_{j}\right)+\lambda^{2}\right.$

3. Melakukan tiga langkah dibawah untuk seluruh data yang ada untuk memperbaharui nilai $E$ (error) dan $a$ (alpha).

a. $E i=\sum l j=1$ aj $D i j$

b. $\delta a_{i}=\min \left\{\max \left[\gamma\left(1-E_{1}\right),-a_{i}\right], C-a_{i}\right\}$

c. $a_{i}=a_{i}+\delta a_{i}$

4. Kembali ke langkah 3 sampai $a$ konvergen

5. Selesai.

\subsubsection{Interjection dan Punctuation}

Data telah di ketahui nilainya pasca melewati proses klasifikasi dengan metode Support Vector Machine, kemudian akan di ambil yang bernilai true negative. Data yang bernilai true negative tersebut akan di berikan fitur ekstraksi, yakni Interjection dan Punctuation. Data yang telah di tambahkan fitur tersebut akan di klasifikasikan kembali.

Karena saat preprocessing semua tanda baca akan di hapus, maka untuk dapat mengimplementasikan pemberian fitur punctuation, penulis kembali menggunakan data awal yang di sesuaikan dengan data hasil klasifikasi, agar dapat mengembalikan nilai 1 jika menemukan punctuation di dalam sebuah tweet.

\subsection{Pengujian}

Confusion Matrix merupakan metode pengujian yang digunakan untuk mengetahui tingkat keakuratan suatu model teknik klasifikasi. Terdapat beberapa jenis pengujian yang akan di lakukan di metode pengujian confusion matrix ini, antara lain recall, precision, F1-Score, dan accuracy. Berikut Tabel 9 confusion matrix.

Tabel 9. Tabel Confusion Matrix

\begin{tabular}{cccc}
\hline \multicolumn{4}{c}{ Tabel 9. Tabel Confusion Matrix } \\
\hline & \multicolumn{3}{c}{ Actual } \\
\cline { 2 - 4 } & Yes & No \\
\cline { 2 - 4 } & Yes & TP & FP \\
\cline { 3 - 4 } & No & FN & TN \\
\hline
\end{tabular}

Yang mana:

a. TP (True Positive) = Jumlah sampel bernilai true yang diprediksi benar

b. $\quad$ TN (True Negative) = Jumlah sampel bernilai false yang diprediksi secara benar

c. FP (False Positive $)=$ Jumlah sampel bernilai false yang salah diprediksi sebagai sampel bernilai true

d. FN (False Negative) = Jumlah sampel bernilai true yang salah diprediksi sebegai sampel bernilai true

\section{Hasil Penelitian dan Pembahasan}

\subsection{Hasil Analisis Sentimen}

Pada tahap ini, di lakukan perhitungan pengujian dari hasil klasifikasi sentimen analisis yang telah dilakukan menggunakan algoritma support vector machine, yang mana perhitungan tersebut akan mengeluarkan nilai seperti akurasi, recall, dan precision. Berikut Tabel $10 \mathrm{l}$ hasil dari pengujian.

Tabel 10. Hasil pengujian sentiment analysis

\begin{tabular}{ccccc}
\hline & Precision & Recall & F1 Score & Akurasi \\
\hline Positif & $90 \%$ & $72 \%$ & $80 \%$ & \multirow{2}{*}{$80 \%$} \\
\hline Negatif & $71 \%$ & $90 \%$ & $79 \%$ & \\
\hline
\end{tabular}

Pada Tabel 10 di atas, dapat di ketahui nilai-nilai yang keluar dari masing-masing tipe pengujian. pNilai akurasi yang di dapatkan dari pengujian analisis sentimen ini sebesar $80 \%$. 


\subsection{Hasil Sentimen Radikal}

Sama seperti tahap pengujian sentimen analisis sebelumnya, di lakukan perhitungan pengujian dari hasil klasifikasi sentimen radikal yang beberapa kali telah dilakukan menggunakan algoritma SVM, yang mana perhitungan tersebut akan mengeluarkan nilai seperti akurasi, recall, dan precision. Berikut tabel hasil dari pengujian.

\begin{tabular}{ccccc}
\multicolumn{4}{c}{ Tabel 11. Hasil Pengujian Sentiment } & Redikal tanpa Fitur Punctuation dan Interjection \\
\hline & Precision & Recall & F1 Score & Akurasi \\
\hline Non Radikal & $91 \%$ & $91 \%$ & $93 \%$ & \multirow{2}{*}{$93 \%$} \\
\hline Radikal & $95 \%$ & $95 \%$ & $93 \%$ & \\
\hline
\end{tabular}

Pada Tabel 11 di atas merupakan hasil klasifikasi dari data berkategori true negative yang di dapatkan dari hasil klasifikasi analisis sentiment positif dan negatif. Klasifikasi dilakukan tanpa menambahkan kedua fitur. Nilai akurasi yang didapatkan pada pengujian sentimen radikal ini ialah sebesar $93 \%$.

Tabel 12. Hasil Pengujian Sentimen Radikal dengan Fitur Punctuation dan Interjection n=200

\begin{tabular}{ccccc}
\hline & Precision & Recall & F1 Score & Akurasi \\
\cline { 1 - 3 } Non Radikal & $92 \%$ & $97 \%$ & $94 \%$ & \multirow{2}{*}{$94 \%$} \\
\hline Radikal & $97 \%$ & $92 \%$ & $94 \%$ & \\
\hline
\end{tabular}

Tabel 12 merupakan hasil klasifikasi dari data berkategori true negative yang di dapatkan dari hasil klasifikasi analisis sentiment positif dan negatif. data tersebut kemudian di tambahkan dengan fitur punctuation dan interjection dengan jumlah 200 kata interjection. Nilai akurasi yang di dapatkan pada pengujian sentimen radikal ini meningkat menjadi $94 \%$.

Tabel 13. Hasil Pengujian Sentimen Radikal dengan Fitur Punctuation dan Interjection $n=150$

\begin{tabular}{ccccc} 
& Precision & Recall & F1 Score & Akurasi \\
\hline Non Radikal & $91 \%$ & $91 \%$ & $93 \%$ & \multirow{2}{*}{$93 \%$} \\
\hline Radikal & $96 \%$ & $96 \%$ & $93 \%$ & \\
\hline
\end{tabular}

Pada Tabel 13 di atas merupakan hasil klasifikasi sentiment radikal dengan data true negative, masih dengan cara yang sama namun dengan jumlah interjection yang berbeda yakni sebanyak 150 kata interjection. Nilai akurasi yang di dapatkan menjadi 93\%.

Tabel 14. Hasil Pengujian Sentimen Radikal dengan Fitur Punctuation dan Interjection $n=100$

\begin{tabular}{ccccc} 
& Precision & Recall & F1 Score & Akurasi \\
\hline Non Radikal & $91 \%$ & $97 \%$ & $94 \%$ & \multirow{2}{*}{$94 \%$} \\
\hline Radikal & $97 \%$ & $91 \%$ & $94 \%$ & \\
\hline
\end{tabular}

Pada Tabel 14 di atas terlihat tingkat akurasi meningkat lagi dengan menggunakan interjection sebanyak 100 kata. Sama halnya dengan percobaan pada jumlah interjection sebanyak 200 kata yang memiliki tingkat akurasi $94 \%$, namun keduanya memiliki perbedaan tipis pada nilai precision dan recall.

\section{Kesimpulan}

Tahun politik merupakan tahun yang rawan akan tulisan-tulisan yang bernada negatif, terutama tulisan-tulisan para pelaku politik di twitter. Penelitian ini mengusulkan untuk melakukan analisis sentimen guna mengambil data yang bernilai negatif yang termasuk kedalam kategori true negative dan di lakukan penambahan fitur kedalam data tersebut.

Terdapat dua fitur yang di gunakan pada tweet yang bernilai true negative, yakni punctuation dan interjection. Data yang telah di berikan fitur tersebut, akan di klasifikasikan kembali dengan algoritma SVM. Berdasarkan hasil penelitian, tingkat akurasi yang di peroleh pada dari analisis sentimen yang diklasifikasikan dengan algoritma SVM yang di sediakan oleh library scikit-learn menunjukkan angka $80 \%$. Data true negative yang didapatkan dari hasil klasifikasi analisis sentimen sebelumnya akan diklasifikasikan kembali menggunakan algoritma support vector machine dengan dan tanpa fitur punctuation dan interjection.

REPOSITOR, Vol. 2, No. 7, Juli 2020: 905-914 
Tingkat akurasi tanpa menggunakan fitur punctuation dan interjection yang didapatkan ialah sebesar $93 \%$. Namun, jika data tersebut di tambahkan fitur punctuation dan interjection yang beberapa kali dilakukan, didapatkan tingkat akurasi sebesar $94 \%$ dengan jumlah interjection 100 kata, 93\% dengan jumlah interjection 150 kata, dan 94\% dengan jumlah interjection 200 kata.

Berdasarkan percobaan tersebut, tingkat akurasi terbaik yang didapatkan sebesar $94 \%$ melalui klasifikasi dengan jumlah interjection sebanyak 200 kata, walaupun memiliki tingkat akurasi yang sama dengan klasifikasi interjection dengan jumlah 100 kata, namun nilai dari precision maupun recall yang di tujukkan memberikan angka yang sedikit berbeda, yang mana hasil klasifikasi dengan interjection 200 kata memiliki nilai precision dan recall yang lebih besar.

\section{Saran}

Berdasarkan penelitian yang telah dilakukan oleh penulis telah di ambil kesimpulan seperti yang dijelaskan di atas, seperti halnya penelitian lainnya penelitian yang telah dilakukan masih memiliki beberapa kekurangan, sehingga penulis mengharapkan penelitian ini untuk dikembangkan lebih lanjut, saran yang dapat diberikan penulis berdasarkan hasil penelitian yaitu:

1. Banyaknya jumlah dataset sangat dalam penelitian ini, semakin banyaknya data yang digunakan justru akan semakin baik di dalam penelitian.

2. Pengacakan data adalah hal krusial yang dapat menyebabkan data terdistribusi secara natural.

3. Pembagian nilai label di dalam dataset yang kemudian di pecah kedalam bentuk data latih dan data uji lebih baik seimbang.

4. Algoritma klasifikasi yang di gunakan perlu mendapatkan algoritma klasifikasi pembanding, terutama algoritma klasifikasi deep learning.

\section{Referensi}

[1] R. WP, A. Novianty, and C. Setianingsih, "Analisis Sentimen Menggunakan Support Vector Machine dan Maximum Entropy," vol. 4, no. 2, p. 2389, 2017.

[2] G. A. Buntoro, "Analisis Sentimen Hatespeech Pada Twitter Dengan Metode Naïve Bayes Classifier Dan Support Vector Machine," J. Din. Inform., vol. 5, no. 2, pp. 1-12, 2016.

[3] P. P. A. Ferdi Alvianda, Indriati, "Analisis Sentimen Konten Radikal Di Media Sosial Twitter Menggunakan Metode Support Vector Machine (SVM)," vol. 3, no. 1, pp. 7828-7833, 2019.

[4] D. A. P. Rahayu, S. Kuntur, and N. Hayatin, "Sarcasm detection on Indonesian twitter feeds," Int. Conf. Electr. Eng. Comput. Sci. Informatics, vol. 2018-Octob, pp. 137-141, 2018.

[5] B. Andrianto and S. Adinugroho, "Analisis Sentimen Konten Radikal Melalui Dokumen Twitter Menggunakan Metode Backpropagation," J. Pengemb. Teknol. Inf. dan IImu Komput., vol. 2, no. 12, pp. 7380-7385, 2018

[6] A. Z. H. Khan, M. Atique, and V. . Thakare, "Sentiment analysis using Support Vector Machine," I4CT 2014 - 1st Int. Conf. Comput. Commun. Control Technol. Proc., vol. 5, no. 4, pp. 333-337, 2014.

[7] V. I. Santoso, G. Virginia, and Y. Lukito, "Penerapan Sentiment Analysis Pada Hasil Evaluasi Dosen Dengan Metode Support Vector Machine," J. Transform., vol. 14, no. 2, p. 72, 2017.

[8] O. Somantri, D. Apriliani, J. T. Informatika, P. Harapan, and B. Tegal, "Support Vector Machine Berbasis Feature Selection Untuk Sentiment Analysis Kepuasan Pelanggan Terhadap Pelayanan Support Vector Machine Based on Feature Selection for Sentiment Analysis Customer Satisfaction on Culinary," vol. 5, no. 5, pp. 537-548, 2018.

[9] A. Perdana and M. T. Furqon, "Penerapan Algoritma Support Vector Machine ( SVM ) Pada Pengklasifikasian Penyakit Kejiwaan Skizofrenia ( Studi Kasus: RSJ . Radjiman Wediodiningrat , Lawang )," J. Pengemb. Teknol. Inf. dan IImu Komput. Univ. Brawijaya, vol. 2, no. 9, pp. 3162-3167, 2018.

[10] I. I Made Budi Surya Darma, Rizal Setya Perdana, "Penerapan Sentimen Analisis Acara Televisi Pada Twitter Menggunakan Support Vector Machine dan Algoritma Genetika sebagai Metode Seleksi Fitur," J. Pengemb. Teknol. Inf. dan Ilmu Komput., vol. 2, no. 3, pp. 998-1007, 2018. 
REPOSITOR, Vol. 2, No. 7, Juli 2020: 905-914 